\title{
CONTROLLED QUEUEING SYSTEMS ${ }^{1}$
}

\author{
Submitted for publication to \\ CRC Press \\ Boca Raton, FL USA \\ V. RYKOV \\ Applied Math Dept., Oil and Gas State Academy \\ Leninsky prosp. 65, 117917 Moscow Russia \\ M. YU. KITAEV \\ 2nd Krasnoselskaja str. 2, app. 209 \\ Moscow Russia
}

The purpose of this book is to collect together the newest results on the theory of Markov decision processes needed for queueing models and to demonstrate their applications to main types of control in queueing systems. These types are:

- control of arrivals;

- control of service mechanisms;

- control of service discipline.

This book, to the best of our knowledge, is the first one which is completely devoted to the subject pointed out in its title. We realize that an attempt to be encyclopedic would defeat the purpose of the book because of the overwhelming amount of material. Therefore, within each of these classes we have chosen representatives where the general ideas were expressed in the most clear form.

The emphasis is placed on conditions providing "good" structural properties of optimal strategies such as monotonicity, threshold and hysteretic character, and priority. These properties allow us to restrict the range of search of the optimal strategy and sometimes to explicitly construct it.

We hope that this book will turn out to be useful to applied mathematicians interested in queueing systems, specialists in system analysis and performance evaluation, and for graduate and postgraduate students of corresponding orientations.

Each chapter is followed by exercises which form an essential logical part of the book. In most exercises, the reader is offered to complete technical fragments of proofs. Other exercises, grouped in series, are intended to lead the reader step by step to justification of some facts given in the text as auxiliary. This strategy allowed us to reduce proofs and emphasize guiding ideas.

In bibliographical remarks as a rule, we only refer to those sources which were directly used in the text. It was not our intention to give an overall picture of the literature on one topic or another. The reader, interested in the history of the subject or in topics not treated in the book, may consult recent surveys which are cited in the book.

\footnotetext{
${ }^{1}$ Please direct all inquiries to CRC Press, Inc., 2000 Corporate Blvd. NW, Boca Raton, FL 33431 USA. 


\section{Contents}

1. Semi-Regenerative Decision Models 1

1.2. Description of basic decision model 1

1.2.1. Histories and strategies 2

1.2.2. Cost functionals 4

1.2.3. Markov properties 5

$\begin{array}{ll}\text { 1.3. } & \text { Rigorous definitions and assumptions }\end{array}$

1.4. Examples of controlled queues $\quad 9$

$\begin{array}{ll}\text { 1.5. Optimization problems } & 17\end{array}$

1.6. Renewal kernels of the decision model $\quad 19$

1.7. Special classes of strategies 24

1.8. Sufficiency of Markov strategies $\quad 26$

1.9. Remarks and exercises $\quad 30$

2. Dynamic Programming 33

2.1. Introduction $\quad 33$

2.2. Discounting in continuous time $\quad 34$

\begin{tabular}{ll}
2.3. & Dynamic programming equation \\
\hline
\end{tabular}

2.4. Bellman functions $\quad 41$

2.5. Finite horizon problem $\quad 44$

2.6. Infinite-horizon discounted-cost problem 46

2.7. Random-horizon problem $\quad 52$

2.8. Remarks and exercises $\quad 56$

$\begin{array}{ll}\text { 3. Average Cost Criterion } & 61\end{array}$

3.1. Introduction 61

3.2. Preliminaries: weak topology, limit passages 63

3.3. Preliminaries: taboo-probabilities, limit theorems for Markov renewal processes 68

$\begin{array}{ll}3.4 . & \text { Notation, recurrence-communication assumptions, examples }\end{array}$

3.5. Existence of optimal policies $\quad 83$

3.6. Existence of optimal strategies. General criterion 88

3.7. Existence of optimal strategies. Sufficient condition 90

$\begin{array}{ll}3.8 . & \text { Optimality equation }\end{array}$

3.9. Constrained average-cost problem $\quad 103$

3.10. Average-cost optimality as limiting case of discounted-cost optimality 106

$\begin{array}{ll}3.11 . & \text { Remarks and exercises } \\ & 112\end{array}$

4. Continuously Controlled Jump Markov Processes 119

$\begin{array}{ll}\text { 4.1. Introduction } & 119\end{array}$

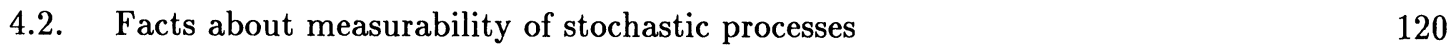

4.3. Marked point processes and random measures $\quad 124$

$\begin{array}{ll}\text { 4.4. The predictable sigma-algebra } & 127\end{array}$

4.5. Dual predictable projection of random measures 130

4.6. Definition of controlled jump Markov processes 137

4.7. An $\mathrm{M} / \mathrm{M} / 1$ queue with controllable input and service rate 142

4.8. Dynamic programming $\quad 146$

4.9. Optimization problems 151

4.10. Remarks and exercises 152 
5. Structured Optimization Problems for Decision Processes 157

$\begin{array}{ll}\text { 5.1. Introduction } & 157\end{array}$

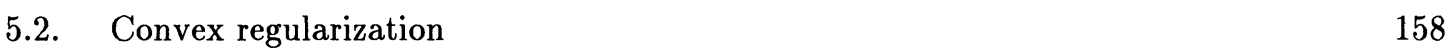

5.3. Submodular and supermodular functions 161

5.4. Existence of monotone solutions for optimization problems 165

$\begin{array}{ll}\text { 5.5. Processes with bounded drift } & 168\end{array}$

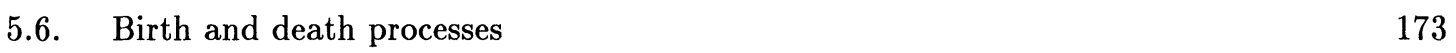

$\begin{array}{ll}\text { 5.7. Remarks and exercises } & 177\end{array}$

6. Control of Arrivals $\quad 179$

$\begin{array}{lll}\text { 6.1. } & \text { Introduction } & 179\end{array}$

6.2. The model description $\quad 180$

6.3. Finite-horizon discounted-cost problem 182

$\begin{array}{lll}\text { 6.4. Cost functionals } & 185\end{array}$

6.5. Infinite-horizon case with and without discounting 190

6.6. Optimal dynamic pricing policy: model 194

6.7. Optimal dynamic pricing policy: results $\quad 196$

$\begin{array}{ll}\text { 6.8. Remarks and exercises } & 201\end{array}$

7. Control of Service Mechanism 205

$\begin{array}{ll}\text { 7.1. Introduction } & 205\end{array}$

7.2. Description of the system 206

$\begin{array}{ll}\text { 7.3. Static optimization problem } & 210\end{array}$

7.4. Optimal policies for the queueing process 213

$\begin{array}{ll}\text { 7.5. Service system with two interacting servers } & 217\end{array}$

7.6. Analysis of optimality equation $\quad 219$

$\begin{array}{ll}\text { 7.7. } & \text { Remarks and exercises } \\ & 224\end{array}$

8. Optimal Control in Models with Several Classes of Customers 227

8.1. Description of models and processes 227

8.2. Associated controlled processes 230

8.3. Existence of optimal simple strategies for the systems with alternating priority 234

8.4. Existence of optimal simple strategies for the system with feedback 239

8.5. Equations for stationary distributions 242

8.6. Stationary characteristics of the systems with alternating priority 244

8.7. Stationary characteristics of the systems with feedback 250

8.8. Models with alternating priority. Linear programming problem 253

8.9. Linear programming problem in the model with feedback 259

8.10. Model with periods of idleness and discounted-cost criterion 262

8.11. Basic formulas 265

8.12. Construction of optimal modified priority discipline 269

8.13. Remarks and exercises $\quad 275$

$\begin{array}{ll}\text { Bibliography } & 279\end{array}$

$\begin{array}{ll}\text { Index } & 285\end{array}$ 


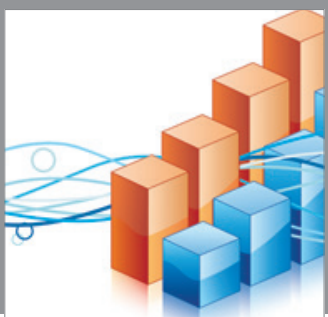

Advances in

Operations Research

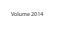

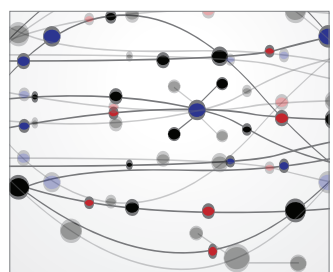

\section{The Scientific} World Journal
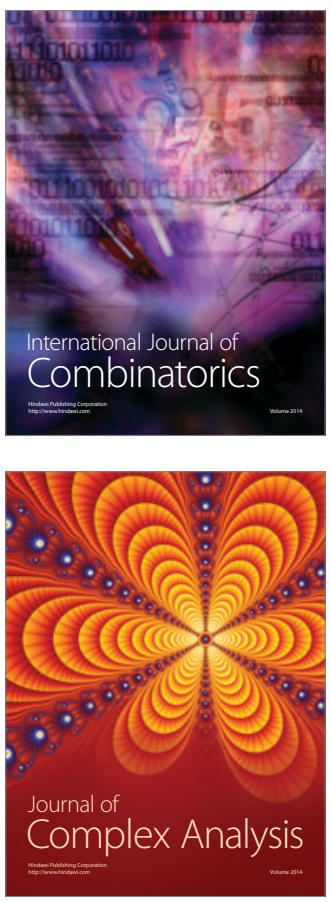

International Journal of

Mathematics and

Mathematical

Sciences
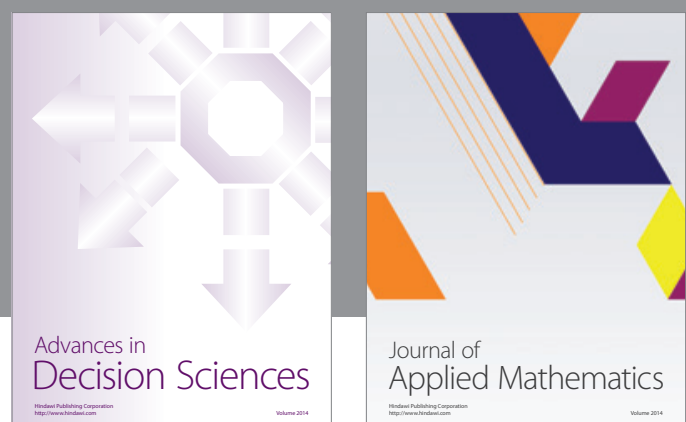

Journal of

Applied Mathematics
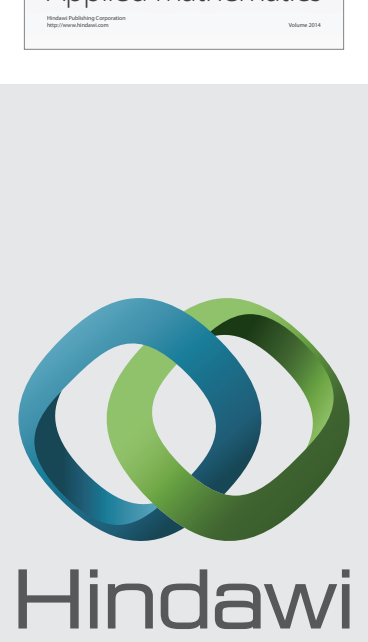

Submit your manuscripts at http://www.hindawi.com
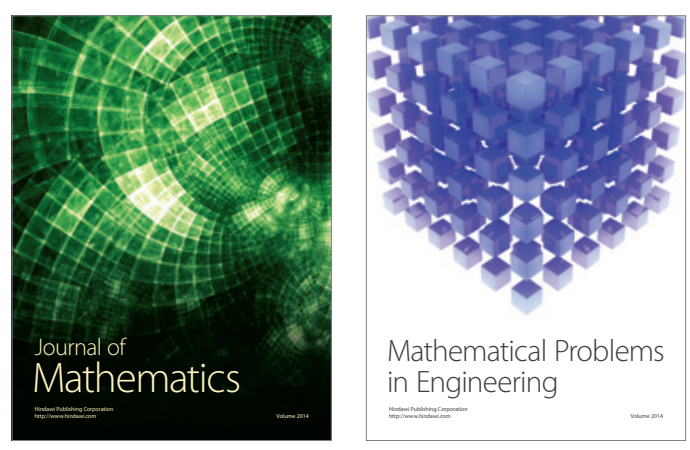

Mathematical Problems in Engineering
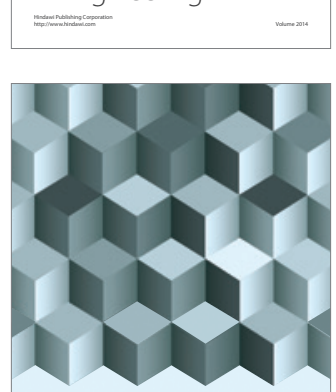

Journal of

Function Spaces
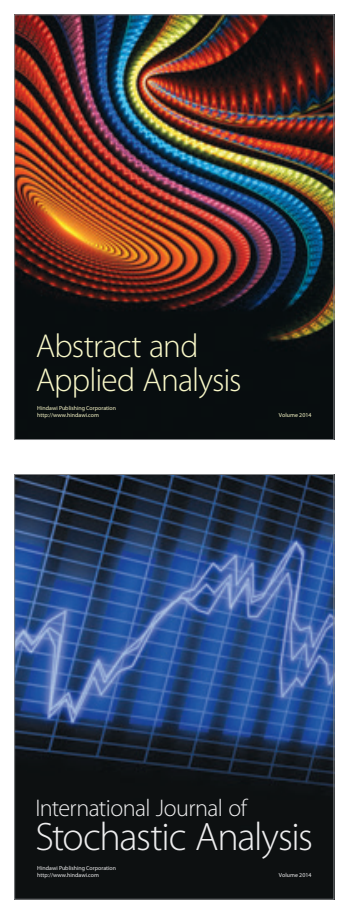

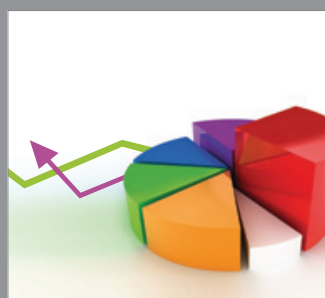

ournal of

Probability and Statistics

Promensencen
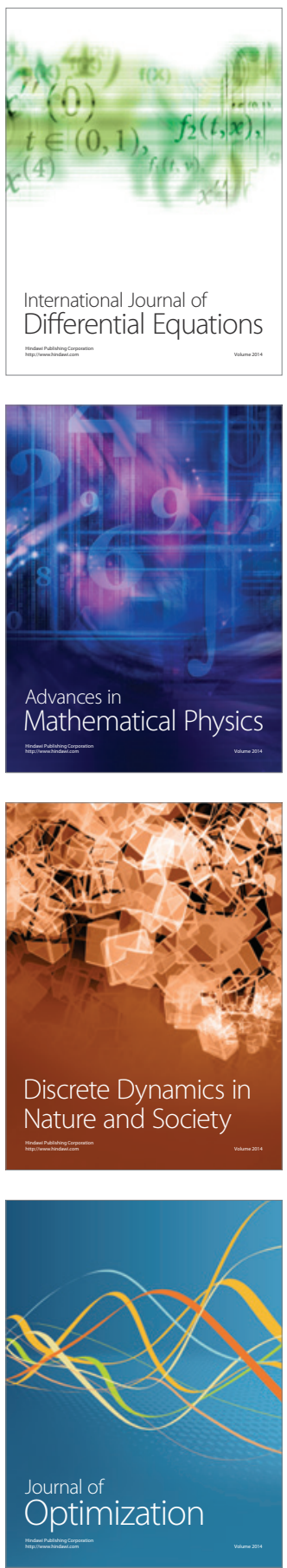